\title{
Younger age and valve oversizing are predictors of structural valve deterioration after pulmonary valve replacement in patients with tetralogy of Fallot
}

\author{
Peter C. Chen, MD, Maggie S. Sager, BA, David Zurakowski, PhD, Frank A. Pigula, MD, \\ Christopher W. Baird, MD, John E. Mayer, Jr, MD, Pedro J. del Nido, MD, and Sitaram M. Emani, MD
}

Objective: We sought to identify predictors of structural valve deterioration after pulmonary valve replacement in patients with tetralogy of Fallot.

\begin{abstract}
Methods: A retrospective review of 227 patients with tetralogy of Fallot who underwent stented bioprosthetic pulmonary valve replacement at Children's Hospital Boston between 1994 and 2009 was performed. Patient and valve characteristics were assessed as potential predictors of structural valve deterioration by using univariate and multivariable analysis. Freedom from pulmonary valve reintervention and structural valve deterioration were determined by using Kaplan Meier analysis.
\end{abstract}

Results: Two hundred twenty-nine pulmonary valve replacement operations were performed, with no early mortalities. Freedom from reintervention and structural valve deterioration were $94 \%$ (95\% confidence interval, $87 \% \quad 100 \%$ ) and $74 \%$ (95\% confidence interval, $63 \% \quad 85 \%$ ) at 5 years, respectively, and median time to reintervention was 6.4 years (range, 210.1 years). Younger age and higher indexed valve internal diameter were predictors of reduced time to structural valve deterioration. Among patients aged less than 20 years at the time of pulmonary valve replacement, indexed valve internal diameter was a significant predictor of increased risk of structural valve deterioration. Valve manufacturer was not a significant predictor of structural valve deterioration.

Conclusions: Younger age at the time of pulmonary valve replacement and valve oversizing in patients less than 20 years of age at the time of pulmonary valve replacement were significant predictors of structural valve deterioration and could potentially affect the timing of pulmonary valve replacement and the extent of valve oversizing in small children. No statistically significant difference in valve performance was seen between bioprosthetic valve types at short-term follow-up. (J Thorac Cardiovasc Surg 2012;143:352-60)

Earn CME credits at

http://cme.ctsnetjournals.org

Complete surgical repair of tetralogy of Fallot (TOF) has been successfully performed since the 1950s. Although favorable long-term outcomes have been documented, an increasing number of patients are requiring reoperation after initial TOF repair for pulmonary regurgitation (PR). ${ }^{1,2}$ Although the majority of patients with significant PR are

From the Department of Cardiovascular Surgery, Children's Hospital Boston, Boston, Mass.

Disclosures: Authors have nothing to disclose with regard to commercial support.

Read at the 91st Annual Meeting of The American Association for Thoracic Surgery, Philadelphia, Pa, May 7-11, 2011.

Received for publication May 9, 2011; revisions received Oct 6, 2011; accepted for publication Oct 28, 2011; available ahead of print Dec 9, 2011.

Address for reprints: Sitaram M. Emani, MD, Cardiovascular Surgery, Children's Hospital Boston, 300 Longwood Ave, Boston, MA 02115 (E-mail: Sitaram. Emani@cardio.chboston.org).

0022-5223/\$36.00

Copyright (c) 2012 by The American Association for Thoracic Surgery doi: $10.1016 /$ j.jtcvs.2011.10.079 asymptomatic for many years, they remain at risk for progressive right ventricular (RV) dilatation and reduced ventricular function, development of arrhythmias, or sudden death. ${ }^{3}$ Current indications for pulmonary valve replacement (PVR) include a right ventricular end-diastolic volume index (RVEDVI) of $150 \mathrm{~mL} / \mathrm{m}^{2}$ or greater, an RV ejection fraction of $45 \%$ or less, right ventricular outflow tract (RVOT) aneurysm, and significant clinical symptoms. ${ }^{4}$ PVR in these patients has previously been demonstrated to provide significant improvement in RV function and exercise tolerance. ${ }^{5,6}$

Although PVR with a bioprosthetic valve has become standard practice in patients with TOF who demonstrate indications for surgical intervention, durability and risk factors for structural valve deterioration (SVD) and reintervention in the RVOT position have not been defined. Information regarding the durability of existing prostheses will affect recommendations regarding the timing of PVR., Long-term data are available for bioprosthetic valve durability in the aortic position, ${ }^{8-10}$ and these data are typically extrapolated to decision making and counseling for PVR. Therefore this study sought to identify predictors for SVD after stented bioprosthetic PVR in patients with TOF who had undergone previous complete TOF repair. 


Abbreviations and Acronyms
$\begin{aligned} \text { CE } & =\text { Carpentier Edwards } \\ \text { ID } & =\text { internal diameter } \\ \text { MRI } & =\text { magnetic resonance imaging } \\ \text { PR } & =\text { pulmonary regurgitation } \\ \text { PS } & =\text { pulmonary stenosis } \\ \text { PVR } & =\text { pulmonary valve replacement } \\ \text { RV } & =\text { right ventricular } \\ \text { RVEDV } & =\text { right ventricular end-diastolic volume } \\ \text { RVEDVI } & =\text { right ventricular end-diastolic volume } \\ & \text { index } \\ \text { RVEF } & =\text { right ventricular ejection fraction } \\ \text { RVOT } & =\text { right ventricular outflow tract } \\ \text { SVD } & =\text { structural valve deterioration } \\ \text { TOF } & =\text { tetralogy of Fallot } \\ \text { TR } & =\text { tricuspid regurgitation }\end{aligned}$

\section{MATERIALS AND METHODS}

\section{Patient Population}

Institutional review board approval was obtained before all data collec tion. All patients with TOF (n 227) who underwent stented bioprosthetic PVR between January 1, 1994, and December 31, 2009, at Children's Hos pital Boston were included in the study. Exclusion criteria included patients who received a pulmonary homograft or mechanical valve as their method of RVOT reconstruction. At our institution, placement of a stented biopros thetic valve, when possible, is preferred over placement of stentless valves or pulmonary homografts because of concerns about durability. The type of stented bioprosthetic valve implanted was based on the surgeon's prefer ence, and the size of the valve implanted was limited by the ability to aug ment the RVOT. All patients were maintained on $81 \mathrm{mg}$ of aspirin postoperatively after bioprosthetic PVR. Follow up was obtained through patients' medical records and direct telephone contact.

\section{Intraoperative Management of the Tricuspid Valve}

Repair of the tricuspid valve at the time of PVR was performed if there was greater than moderate regurgitation or a structural malformation that was unlikely to improve with PVR, such as leaflet perforation, flail leaflet, or distortion secondary to a transvenous pacemaker wire. In the case of structural malformations, a repair was performed for less than moderate tri cuspid regurgitation (TR). The type of repair depended on the mechanism responsible for poor valve function; in most patients closure of the antero septal commissure was performed.

\section{Data Collection}

Demographic, clinical, operative, and imaging data were obtained from patients' medical records. The type of valve implanted and other specifics of the surgical procedures performed were obtained from operative reports. Review of preoperative and postoperative echocardiographic and magnetic resonance imaging (MRI) reports was performed, and relevant measure ments were recorded. Echocardiographic measurements included qualita tive degree of PR, pulmonary stenosis (PS), TR, peak pulmonary valve gradient (in millimeters of mercury), and estimated RV pressures (in mil limeters of mercury) by TR jet. Data recorded from MRI reports included right ventricular ejection fraction (RVEF), pulmonary and tricuspid regur gitant fractions, right ventricular end diastolic volume (RVEDV), and RVEDVI. Preoperative imaging data were collected from studies closest in proximity to the date of the operation, and postoperative imaging data were collected from the most recent studies.

\section{Structural Valve Deterioration}

The development of SVD was defined as the need for repeat PVR or pul monary valve intervention at catheterization or development of PR or PS graded at greater than or equal to moderate on follow up echocardiographic analysis or MRI, as defined by recent guidelines. ${ }^{11}$ Follow up for SVD in cluded patients undergoing first time and repeat PVR.

\section{Statistical Analysis}

Data are described as numbers with frequencies and percentages, me dians with interquartile ranges, and means with standard deviations. Actu arial freedom from pulmonary valve reintervention and SVD were determined by using the Kaplan Meier method, with age groups compared by using the log rank test and the Greenwood formula used for constructing $95 \%$ confidence intervals (CIs) around the curves. ${ }^{12}$ Paired $t$ tests were used to assess improvements in postoperative imaging data, and the Wilcoxon signed rank test was applied to compare preoperative and follow up grades of PR, PS, and TR. Two tailed $P$ values of less than .05 were considered statistically significant. To control for possible confound ing variables, the multivariable Cox proportional hazards regression model was applied to identify significant risk factors for SVD and included all var iables with statistical significance on univariate analysis. ${ }^{13}$ In patients less than 20 years old at the time of PVR, we applied logistic regression mod eling to estimate the probability of SVD with a $95 \%$ CI based on indexed valve internal diameter (ID). Statistical analysis was performed with the SPSS software package (version 19.0; SPSS, Inc, Chicago, Ill).

\section{RESULTS \\ Patients' Characteristics}

A total of 227 patients with TOF undergoing 229 PVR operations were included in the study. Preoperative imaging and complete follow-up with postoperative imaging after discharge were available in $176(77 \%)$ of 229 patients. Demographic and baseline clinical data of the study population are summarized in Table 1. All patients had previously undergone TOF repair. The congenital heart disease diagnosis of TOF with pulmonary atresia was noted in 46 (20\%) patients, and TOF with absent pulmonary valve was noted in $13(6 \%)$ patients. The median duration of postoperative follow-up was 2.3 years (range, 0.114 .6 years), and mean duration was $3.2 \pm 2.8$ years. Both MRI and echocardiographic data were available in 57 (25\%) patients preoperatively and postoperatively. For the remainder of patients with available imaging data, echocardiography was the imaging modality used for data analysis.

\section{Pulmonary Valve Replacement}

Operative PVR data are summarized in Table 2. Four types of stented bioprosthetic valves were implanted: the Carpentier Edwards (CE; Model 2700; Edwards Lifesciences, Irvine, Calif) Perimount valve, the CE Magna valve (Model 3000 TFX), the Sorin (Sorin Group, Milan, Italy) Mitroflow valve, and the CE porcine valve (Model 2625). Duration of follow-up after PVR differed depending on the valve type implanted: CE Perimount, 5.5 years $(0.510$ 
TABLE 1. Patients' characteristics at the time of PVR

\begin{tabular}{lc}
\hline \multicolumn{1}{c}{ Characteristic } & All patients $(\mathbf{n}$ 227) \\
\hline Sex & \\
Male & $142(63 \%)$ \\
Female & $85(37 \%)$ \\
Median age at TOF repair $(y)$ & $0.8(0.0137 .0)$ \\
Median age at PVR (y) & $19.4(0.458 .1)$ \\
Median time to PVR (y) & $17.5(0.3746 .13)$ \\
NYHA class & \\
I & $111(49 \%)$ \\
II & $95(41 \%)$ \\
III & $20(9 \%)$ \\
IV & $1(1 \%)$ \\
Preoperative RVEF $(\%)$ & $47 \pm 9$ \\
Preoperative RVEDV $(\mathrm{mL})$ & $290 \pm 116$ \\
Preoperative RVEDVI $\left(\mathrm{mL} / \mathrm{m}^{2}\right)$ & $186 \pm 53$ \\
PR fraction & $0.46 \pm 0.13$ \\
\hline
\end{tabular}

NYHA, New York Heart Association; $P R$, pulmonary regurgitation; $P V R$, pulmonary valve replacement; $R V E D V$, right ventricular end-diastolic volume; $R V E D V I$, right ventricular end-diastolic volume index; $R V E F$, right ventricular ejection fraction; TOF, tetralogy of Fallot.

years); CE Magna, 2.4 years ( 0.36 years); Sorin Mitroflow, 1 year ( 0.12 .7 years); CE porcine valve, 8.7 years (6.0 14.6 years). The majority of patients underwent a concomitant procedure at the time of PVR $(74 \%)$. PVR was performed either within a tube graft conduit or directly into the native RVOT, with or without an anterior patch. All patients survived to discharge, with a median hospital length of stay of 5 days (interquartile range [IQR], 47 days).

The effect of PVR on clinical parameters is summarized in Table 3. Significant improvements were seen in RVEDV, RVEDVI, RV pressure, PV gradient, and PR fraction at the time of the most recent postoperative follow-up imaging. A

TABLE 2. PVR characteristics

\begin{tabular}{|c|c|c|}
\hline Characteristic & All PVRs (n & 229) \\
\hline Presence of RV aneurysm & $44(20 \%)$ & \\
\hline \multicolumn{3}{|l|}{ Valve type } \\
\hline CE Perimount & $61(27 \%)$ & \\
\hline CE Magna & $97(42 \%)$ & \\
\hline Sorin Mitroflow & $58(25 \%)$ & \\
\hline Porcine & $13(6 \%)$ & \\
\hline \multicolumn{3}{|l|}{ Method of implantation } \\
\hline Native RVOT & $211(92 \%)$ & \\
\hline Valve in conduit & $18(8 \%)$ & \\
\hline $\begin{array}{l}\text { Median bioprosthesis size } \\
\quad(\mathrm{mm})\end{array}$ & 27 (range, 19 & 31) \\
\hline \multicolumn{3}{|l|}{ Additional procedures } \\
\hline Aneurysm resection & $10(4 \%)$ & \\
\hline Pulmonary arterioplasty & $43(19 \%)$ & \\
\hline TV intervention & $29(13 \%)$ & \\
\hline Closure of residual shunts & $69(30 \%)$ & \\
\hline RA maze procedure & $10(4 \%)$ & \\
\hline
\end{tabular}

Continuous data are expressed as means \pm standard deviations, and categorical data are expressed as numbers (percentages). $C E$, Carpentier-Edwards; $P V R$, pulmonary valve replacement; $R A$, right atrial; $R V$, right ventricular; $R V O T$, right ventricular outflow tract; $T V$, tricuspid valve.
TABLE 3. Effect of PVR on clinical characteristics

\begin{tabular}{lccr}
\hline \multicolumn{1}{c}{ Characteristic } & Preoperative & Postoperative & P value \\
\hline MRI (n 57) & & & \\
RV ejection fraction & $47 \pm 9$ & $44 \pm 10$ & .002 \\
RVEDV (mL) & $290 \pm 116$ & $244 \pm 113$ & $<.001$ \\
RVEDVI $\left(\mathrm{mL} / \mathrm{m}^{2}\right)$ & $186 \pm 53$ & $141 \pm 51$ & $<.001$ \\
PR fraction & $0.46 \pm 0.13$ & $0.13 \pm 0.11$ & $<.001$ \\
Echocardiography & & & \\
Degree of PR & & & \\
$\quad$ None & $2(1 \%)$ & $90(51 \%)$ & $<.001$ \\
$\quad$ Mild & $6(3 \%)$ & $56(31 \%)$ & \\
$\quad$ Moderate severe & $217(96 \%)$ & $32(18 \%)$ & \\
Degree of PS & & & \\
$\quad$ None & $143(64 \%)$ & $116(65 \%)$ & .164 \\
$\quad$ Mild & $45(20 \%)$ & $52(29 \%)$ & \\
$\quad$ Moderate severe & $36(16 \%)$ & $10(6 \%)$ & \\
Degree of TR & & & \\
$\quad$ None & $61(27 \%)$ & $78(44 \%)$ & $<.001$ \\
$\quad$ Mild & $128(56 \%)$ & $87(49 \%)$ & \\
$\quad$ Moderate severe & $38(17 \%)$ & $12(7 \%)$ & \\
Peak PV gradient (mm Hg) & $38 \pm 23$ & $26 \pm 17$ & .008 \\
Estimated RV pressure & $42 \pm 20$ & $36 \pm 15$ & .011 \\
(mm Hg) & & & \\
\hline
\end{tabular}

Paired $t$ tests were used to assess improvements in the most recent postoperative imaging data, and the Wilcoxon signed-rank test was applied to compare preoperative and follow-up grades of pulmonary regurgitation, pulmonary stenosis, and tricuspid regurgitation. $M R I$, Magnetic resonance imaging; $P R$, pulmonary regurgitation; $P S$, pulmonary stenosis; $P V$, pulmonary valve; $P V R$, Pulmonary valve replacement; $R V$, right ventricular; $R V E D V$, right ventricular end-diastolic volume; $R V E D V I$, right ventricular end-diastolic volume index; $T R$, tricuspid regurgitation.

statistically significant decrease in RVEF was seen at the most recent postoperative MRI. There were 7 postdischarge deaths in the study population, with a median time to mortality of 3.5 years (range, 111 years). Causes of death for these patients were not able to be determined, but in 5 patients there was a study showing no SVD before the time of death. Three of these studies occurred greater than 1 year before the time of death.

\section{Tricuspid Valve Regurgitation}

In our cohort a total of $29(13 \%)$ of 229 patients underwent a concomitant tricuspid valve intervention at the time of PVR. Of these, 26 underwent tricuspid valve repair, and 3 underwent tricuspid valve replacement. There was a significant difference in the number of patients with moderate-to-severe TR preoperatively compared with postoperatively $(17 \%$ vs $7 \%, P<.001)$, as seen in Table 3 . In patients who underwent PVR without concomitant tricuspid valve repair, a decrease in TR grade was observed in $32 \%$ of the patients. However, $15 \%$ experienced an increase in TR grade despite repair. Preoperative TR grade was not predictive of improvement in TR grade postoperatively.

\section{Event-Free Survival}

In defining our population for Kaplan Meier analysis, 7 patient deaths were excluded because the cause of death 


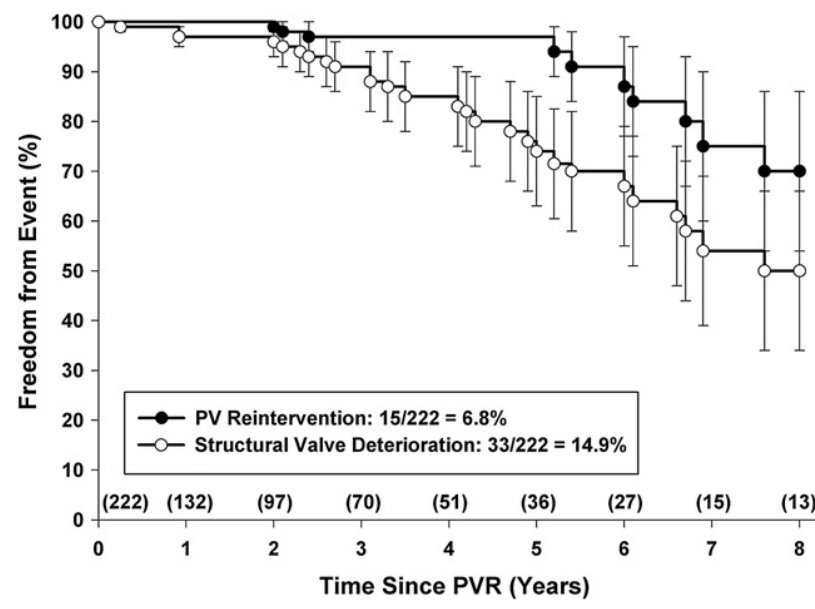

FIGURE 1. Freedom from reintervention and structural valve deteriora tion $(S V D)$. $P V R$, Pulmonary valve replacement.

was unknown and not clearly valve related. Of these 7 deaths, 2 patients did not have any postoperative imaging follow-up, whereas the other 5 had postoperative imaging with no evidence of SVD. SVD (repeat intervention, moderate or severe PR on imaging, or both) was identified in $33(14 \%)$ patients and was observed at a median time after PVR of 4.3 years (range, 0.2514 years). Freedom from SVD at 2, 5, and 7 years was $96 \%$ (95\% CI, 93\% 99\%), $74 \% \quad(95 \% \quad \mathrm{CI}, \quad 64 \% \quad 84 \%)$, and $54 \% \quad(95 \% \mathrm{CI}$, $40 \% 68 \%$ ), respectively (Figure 1). Among the SVD group, 15 of 33 patients ( $45 \%$ in the SVD group and 7\% in the study population) underwent a repeat pulmonary valve intervention. Repeat surgical PVR was performed in $5(2 \%)$ patients, transcatheter stented bovine jugular vein valves were inserted in $7(3 \%)$ patients, and percutaneous pulmonary valve balloon dilation was performed in $3(1 \%)$ patients. Median time to reintervention was 6.7 years (range, 214 years). Freedom from repeat pulmonary valve intervention at 2, 5, and 7 years was $98 \%(95 \% \mathrm{CI}, 95 \%$ $100 \%), 94 \%(95 \% \mathrm{CI}, 88 \% 100 \%)$, and $74 \%$ (95\% CI, $58 \% 90 \%$ ), respectively.

\section{Predictors of SVD}

Characteristics of both patients and valves were assessed as potential predictors of SVD and are summarized in Table 4. All variables that achieved statistical significance by means of univariate analysis were included as candidates within the multivariable Cox proportional hazards regression model. Younger age at the time of PVR (hazard ratio [HR], 0.95; 95\% CI, $0.920 .98 ; P=.04)$ and a higher indexed valve diameter (HR, $1.05 ; 95 \%$ CI, 1.021 .09 ; $P=.03)$ were predictors of earlier time to SVD; however, the 2-way interaction was also significant $(P=.01)$, revealing that indexed valve ID was predictive of outcome only in younger patients at the time of PVR. Indexed valve ID was found to be inversely correlated with age (Spearman
TABLE 4. Risk factors for structural valve deterioration

\begin{tabular}{|c|c|c|c|}
\hline \multirow[b]{2}{*}{ Variable } & \multirow{2}{*}{$\begin{array}{c}\begin{array}{c}\text { Univariate } \\
\text { analysis }\end{array} \\
P \text { value }\end{array}$} & \multicolumn{2}{|c|}{$\begin{array}{l}\text { Multivariable Cox } \\
\text { proportional hazards } \\
\text { regression model }\end{array}$} \\
\hline & & $\begin{array}{l}\text { Hazard ratio } \\
\quad(95 \% \text { CI })\end{array}$ & $\begin{array}{c}P \\
\text { value }\end{array}$ \\
\hline Younger age at PVR (y) & $<.0001 *$ & $0.95\left(\begin{array}{ll}0.92 & 0.98\end{array}\right)$ & $.04 \dagger$ \\
\hline Sex & .99 & & .43 \\
\hline Smaller size of implant (mm) & $<.001 *$ & & .35 \\
\hline $\begin{array}{l}\text { Higher indexed valve ID } \\
\qquad\left(\mathrm{mm} / \mathrm{m}^{2}\right)\end{array}$ & $<.001 *$ & $1.05\left(\begin{array}{ll}1.02 & 1.09\end{array}\right)$ & $.03 \dagger$ \\
\hline \multicolumn{4}{|l|}{ Method of implantation } \\
\hline Valve in conduit & $.05^{*}$ & & .31 \\
\hline RV ejection fraction $(\%)$ & .07 & & .44 \\
\hline Increased RVEDV (mL) & $.02 *$ & & .73 \\
\hline $\operatorname{RVEDVI}\left(\mathrm{mL} / \mathrm{m}^{2}\right)$ & .60 & & .77 \\
\hline PR fraction & .80 & & .98 \\
\hline Peak PV gradient $(\mathrm{mm} \mathrm{Hg})$ & .28 & & .86 \\
\hline $\begin{array}{l}\text { Estimated RV pressure (mm } \\
\mathrm{Hg} \text { ) }\end{array}$ & .81 & & .90 \\
\hline Degree of PR & .11 & & .83 \\
\hline Degree of PS & .22 & & .69 \\
\hline Degree of TR & .73 & & .67 \\
\hline \multicolumn{4}{|l|}{ Valve type } \\
\hline \multicolumn{4}{|l|}{ CE Perimount (reference) } \\
\hline CE Magna & $.003^{*}$ & & .77 \\
\hline Sorin Mitroflow & $<.001 *$ & & .68 \\
\hline Porcine & .18 & & .84 \\
\hline
\end{tabular}

$C E$, Carpentier-Edwards; $C I$, confidence interval; $I D$, internal diameter; $P R$, pulmonary regurgitation; $P S$, pulmonary stenosis; $P V$, pulmonary valve; $P V R$, pulmonary valve replacement; $R V$, right ventricular; $R V E D V$, right ventricular end-diastolic volume; $R V E D V I$, right ventricular end-diastolic volume index; $T R$, tricuspid regurgitation. *Significant univariate association. $\dagger$ Significant independent risk factor for structural valve deterioration.

correlation, $-0.60 ; P<.0001)$. When stratifying by age group, freedom from SVD in the younger patient group $(<20$ years of age at the time of PVR) was $61 \%(95 \%$ CI, $43 \% 79 \%)$ compared with $85 \%$ (95\% CI, $73 \%$ $97 \%$ ) in the older patient group ( $\geq 20$ years of age at the time of PVR; median, 30.6 years; range, 20.158 .1 years) at 5 years (Figure 2). The Cox regression model applied to patients less than 20 years of age at the time of PVR indicated a highly significant HR based on higher indexed valve ID (HR, 1.08; 95\% CI, $1.041 .11 ; P<.001$ ), whereas the effect of indexed valve ID among patients 20 years of age or older at the time of PVR was not significant in the Cox regression analysis $(P=.93)$. In addition, $14(93 \%)$ of 15 patients who underwent a pulmonary valve reintervention were less than 20 years old at the time of PVR. There was no effect of sex, preoperative RVEF, RVEDV, RVEDVI, estimated RV pressure, or peak PV gradient on reduced time to SVD. The median size of the valves implanted at age less than 20 years at the time of PVR was $25 \mathrm{~mm}$, whereas the size of the valves implanted at the age of 20 years or greater at the time of PVR was $27 \mathrm{~mm}$. A moderate correlation was also found between age at the 


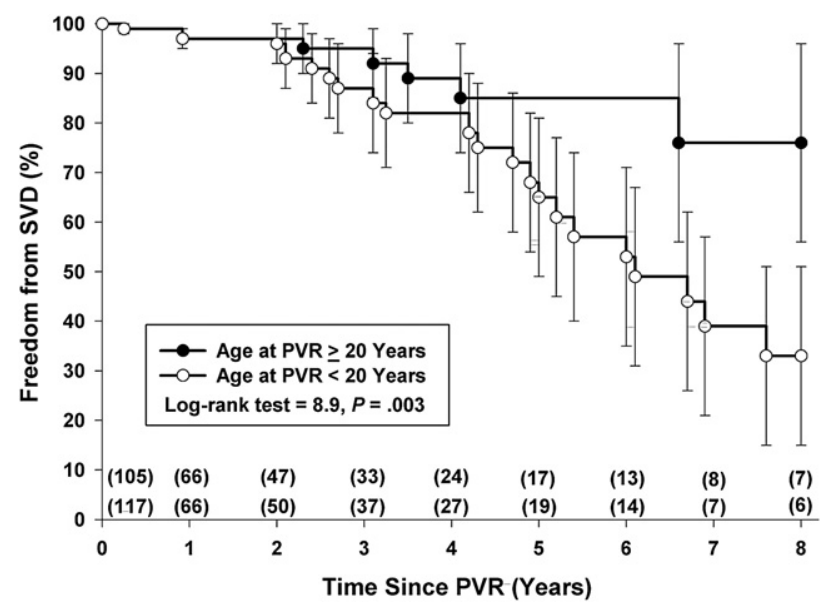

FIGURE 2. Effect of age on freedom from structural valve deterioration. $P V$, Pulmonary valve; $P V R$, pulmonary valve replacement.

time of PVR and the size of the implant (Pearson correlation, $0.51 ; P<.001)$. Smaller implant size, increased RVEDV, and use of conduit did not reach significance when using Cox proportional hazards regression modeling. Valve type implanted was not found to be a predictor of SVD at short-term follow-up. The degree of preoperative PR, PS, and TR did not have a significant effect on the development of SVD.

\section{Valve Oversizing}

The range of indexed valve IDs within our patient population was 8.7 to $60.1 \mathrm{~mm} / \mathrm{m}^{2}$. The correlation identified between age at the time of PVR and indexed valve ID resulted from the increased risk of SVD with increasing indexed valve ID among patients less than 20 years of age at the time of PVR, with no significant relationship seen in patients older than 20 years at the time of PVR. In the younger age group a significant difference in indexed valve ID was seen between the SVD $\left(22.4 \mathrm{~mm} / \mathrm{m}^{2}\right)$ and non-SVD $(16.3$ $\left.\mathrm{mm} / \mathrm{m}^{2}\right)$ groups $(P<.004)$. There was no significant difference in indexed valve ID seen between the SVD (13.8 $\left.\mathrm{mm} / \mathrm{m}^{2}\right)$ and non-SVD $\left(14.2 \mathrm{~mm} / \mathrm{m}^{2}\right)$ groups $(P=.98)$ in the older patient group. Using logistic regression modeling, we estimated the probability of SVD among patients less than 20 years of age at the time of PVR according to indexed valve ID, which is shown as a logistic curve (Figure 3 ) and is statistically significant $(P<.001)$. In addition, logistic regression confirmed that in patients older than 20 years at the time of PVR, indexed valve ID was not predictive $(P=.65)$ of SVD.

\section{DISCUSSION}

Patients experienced significant reductions in RVEDV, RVEDVI, degree of PR and TR, PR fraction, peak PV gradient, and estimated RV pressures after PVR. In our study younger age at the time of PVR was found to be a significant

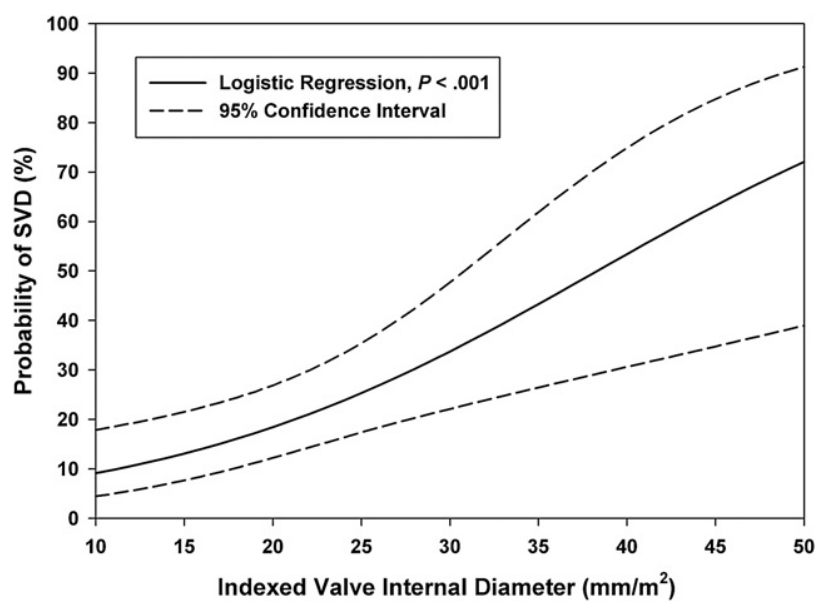

FIGURE 3. Logistic regression curve predicting the probability of struc tural valve deterioration $(S V D)$ according to indexed valve internal diame ter in younger patients.

predictor of reduced time to SVD. Although a moderate correlation was seen between valve size and age at the time of PVR, valve size was not an independent predictor of SVD when performing covariate analysis. However, higher indexed valve ID at implantation, which is indicative of valve oversizing, was an independent predictor of SVD within younger patients. This suggests that valve oversizing in younger patients might contribute to SVD. MRI and echocardiographic measures studied were not predictors of SVD. Valve type and manufacturer were not significant predictors of SVD at short-term follow-up.

Numerous studies have previously evaluated predictors for valve deterioration after RVOT reconstruction in patients with congenital heart disease. ${ }^{14-20}$ These large series have typically included multiple congenital heart disease diagnoses within the study population and have investigated all types of PVR options, including bioprosthetic, homograft, and mechanical valves, with few reviewing stented bioprosthetic valves alone. Despite their variation, younger age at the time of PVR has previously been reported as a risk factor for pulmonary valve reintervention. ${ }^{14,20}$ Zubairi and colleagues ${ }^{20}$ reported age less than 10 years to be a risk factor for repeat pulmonary valve intervention. Caldarone et $\mathrm{al}^{14}$ further identified age range specific risk factors for SVD after they stratified their patient population by age. They identified an increased risk for valve failure with an age at PVR less than their reference range of 15 to 18 years. In our study $93 \%$ of those who underwent a reintervention were younger than 20 years at the time of initial PVR, although our median age at the time of PVR was 19.4 years.

There are several possible explanations for the relationship between younger age and accelerated SVD. Somatic outgrowth of a small conduit is generally considered the most common mode of failure for homograft and xenograft 
conduits implanted into small children. In our cohort there was a correlation between age and the size of the valve implanted, with younger patients receiving smaller valves. However, valve size was not an independent predictor of SVD when accounting for age at implantation. Moreover, SVD in this series was almost exclusively caused by PR rather than PS, suggesting mechanisms other than outgrowth. Interestingly, patients with SVD tended to receive valves with a larger indexed valve ID than patients in the non-SVD group. A significant correlation between higher indexed valve ID and SVD suggests that oversizing of the prosthesis might play a role in accelerated SVD. Even though age, independent of indexed valve ID, was a predictor of SVD, there was a very strong correlation between young age and an oversized valve. Valve oversizing has been associated with accelerated SVD in other types of conduits in the RVOT. ${ }^{21}$ Alterations in flow dynamics across an oversized valve might be the mechanism underlying this phenomenon. Patient-related factors, including immunologic response and hemodynamic factors, might play a role in accelerated valve deterioration as well. Lastly, the bioprostheses studied have been designed for optimal performance in the systemic circulation with higher pressures than in the pulmonary circulation, and differences in leaflet stress characteristics might affect durability.

The correlation of age with SVD might have important implications. Despite younger age being a predictor of SVD, prolonging PVR could expose patients to the deleterious effects of RV dilation. The balance between these competing risks must also include the risk of reoperation when SVD occurs, and this balance might also be affected by the availability of transcatheter valve technology. The optimal timing of PVR for pulmonary valvular insufficiency will depend on the interaction of these multiple risk factors, which will, in turn, depend on the longerterm outcomes after these various interventions.

Significant attention was paid to the correlation identified between age and indexed valve ID. As expected, younger patients were found to have significantly higher indexed valve IDs. Thus, not surprisingly, the phenomenon of valve oversizing was limited to younger children, given more appropriate sizing in adult patients. This association in younger children was depicted in our logistic regression curve, which highlights the increasing probability of SVD with increasing indexed valve IDs. On the basis of these results, we believe oversizing of valves should be limited during PVR in young children.

Our definition of SVD was in accordance with previously published guidelines regarding reporting after cardiac valve interventions. ${ }^{11}$ In contrast to some previous studies addressing long-term outcomes after PVR, this study included patients with moderate PR or PS within our SVD group. This was deemed appropriate because most patients who required reintervention had at least moderate PR at the time of reintervention. The criteria were designed to capture patients who have experienced some level of valve deterioration after PVR and are at risk for eventual reintervention.

Similar to previous reports, ${ }^{7,22}$ this study also identified significant reductions in MRI and echocardiographic parameters postoperatively. A significant improvement in TR was found in $30 \%$ of patients, presumably because of RV remodeling and improved tricuspid leaflet coaptation. Although a significant decrease in RVEF on postoperative MRI at most recent follow-up was seen, this finding is likely due to selection bias because patients with more severe disease are followed more frequently with routine MRI, as opposed to echocardiography alone.

This study is limited by the duration of follow-up, which is associated with the relatively recent use of the CE Magna and Sorin Mitroflow valves, which were US Food and Drug Administration approved in late 2003 and 2007, respectively. No statistically significant difference was identified between valve types as a predictor for SVD when accounting for $\mathrm{du}-$ ration of follow-up. This finding highlights the need for continued long-term patient follow-up after PVR. In addition, this study reports outcomes at a single institution and might not necessarily be generalized to other institutions.

In conclusion, younger age at the time of PVR was found to be a significant predictor of reduced time to SVD, and oversizing of the implanted valve might predispose younger patients to early SVD. These study results could potentially affect the timing of PVR and the extent of valve oversizing in small children. Further long-term follow-up needs to be completed before conclusions can be generated regarding the durability of the various types of stented pericardial valves implanted in the pulmonary position. Additionally, more data will need to be collected to identify the optimal range for valve sizing during PVR in younger children. PVR in this patient population does significantly improve clinical radiographic parameters seen on echocardiographic analysis and MRI.

\section{References}

1. Bacha EA, Scheule AM, Zurakowski D, et al. Long-term results after early primary repair of tetralogy of Fallot. J Thorac Cardiovasc Surg. 2001;122: 154-61.

2. Schamberger MS, Hurwitz RA. Course of right and left ventricular function in patients with pulmonary insufficiency after repair of tetralogy of Fallot. Pediatr Cardiol. 2000;21:244-8.

3. Gatzoulis MA, Balaji S, Webber SA, et al. Risk factors for arrhythmia and sudden cardiac death late after repair of tetralogy of Fallot: a multicentre study. Lancet. 2000;356:975-81.

4. Geva T. Indications and timing of pulmonary valve replacement after tetralogy of Fallot repair. Semin Thorac Cardiovasc Surg Pediatr Card Surg Annu. 2006;11-22.

5. Gengsakul A, Harris L, Bradley TJ, et al. The impact of pulmonary valve replacement after tetralogy of Fallot repair: a matched comparison. Eur J Cardiothorac Surg. 2007;32:462-8.

6. Warner KG, O'Brien PK, Rhodes J, Kaur A, Robinson DA, Payne DD. Expanding the indications for pulmonary valve replacement after repair of tetralogy of Fallot. Ann Thorac Surg. 2003;76:1066-71. 
7. Therrien J, Provost Y, Merchant N, Williams W, Colman J, Webb G. Optimal timing for pulmonary valve replacement in adults after tetralogy of Fallot repair. Am J Cardiol. 2005;95:779-82.

8. Jamieson WR, Germann E, Aupart MR, Neville PH, Marchand MA, Fradet GJ 15-year comparison of supra-annular porcine and PERIMOUNT aortic bioprostheses. Asian Cardiovasc Thorac Ann. 2006;14:200-5.

9. Jamieson WR, Koerfer R, Yankah CA, et al. Mitroflow aortic pericardial bioprosthesis-clinical performance. Eur J Cardiothorac Surg. 2009;36: 818-24.

10. Dalmau MJ, Gonzalez-Santos JM, Blazquez JA, et al. Hemodynamic performance of the Medtronic Mosaic and Perimount Magna aortic bioprostheses: five-year results of a prospectively randomized study. Eur $J$ Cardiothorac Surg. 2011;39:844-52.

11. Akins CW, Miller DC, Turina MI, et al. Guidelines for reporting mortality and morbidity after cardiac valve interventions. J Thorac Cardiovasc Surg. 2008; 135:732-8.

12. Kaplan EL, Meier P. Nonparametric estimation from incomplete observations. $J$ Am Stat Assoc. 1958;53:457-81.

13. Cox D. Regression models and life tables (with discussion). J R Stat Soc B. 1972; 34:187-220.

14. Caldarone CA, McCrindle BW, Van Arsdell GS, et al. Independent factors associated with longevity of prosthetic pulmonary valves and valved conduits. J Thorac Cardiovasc Surg. 2000;120:1022-31.

15. Dos L, Dadashev A, Tanous D, et al. Pulmonary valve replacement in repaired tetralogy of Fallot: determinants of early postoperative adverse outcomes. J Thorac Cardiovasc Surg. 2009;138:553-9.

16. Fiore AC, Rodefeld M, Turrentine M, et al. Pulmonary valve replacement: a comparison of three biological valves. Ann Thorac Surg. 2008;85:1712-8.

17. Henkens IR, van Straten A, Schalij MJ, et al. Predicting outcome of pulmonary valve replacement in adult tetralogy of Fallot patients. Ann Thorac Surg. 2007; 83:907-11

18. Kanter KR, Budde JM, Parks WJ, et al. One hundred pulmonary valve replacements in children after relief of right ventricular outflow tract obstruction. Ann Thorac Surg. 2002;73:1801-7.

19. Shinkawa T, Anagnostopoulos PV, Johnson NC, Watanabe N, Sapru A, Azakie A. Performance of bovine pericardial valves in the pulmonary position. Ann Thorac Surg. 2010;90:1295-300.

20. Zubairi R, Malik S, Jaquiss RD, Imamura M, Gossett J, Morrow WR. Risk factors for prosthesis failure in pulmonary valve replacement. Ann Thorac Surg. 2011; 91:561-5.

21. Askovich B, Hawkins JA, Sower CT, et al. Right ventricle-to-pulmonary artery conduit longevity: is it related to allograft size? Ann Thorac Surg. 2007;84: 907-11.

22. Oosterhof T, Meijboom FJ, Vliegen HW, et al. Long-term follow-up of homograft function after pulmonary valve replacement in patients with tetralogy of Fallot. Eur Heart J. 2006;27:1478-84.

\section{Discussion}

Dr Carl L. Backer (Chicago, Ill). I want to congratulate Dr Chen and his colleagues from Children's Hospital of Boston on their outstanding results with PVR in children and young adults with repaired TOF. A total of 229 operations with no mortality and no significant morbidity is truly a notable achievement.

I believe this review is timely for 2 reasons. One is our current emphasis on pulmonary valve preservation during the initial TOF repair. The fact that 229 patients were believed to need PVR after TOF repair emphasizes the importance of pulmonary valve preser vation, if possible, at the time of the initial operation.

The second reason this presentation is quite timely is the current increase in the use of transcatheter pulmonary valve insertion for appropriate patients. This leads me to my first of 3 questions.

It is my impression in our practice that the availability of trans catheter pulmonary valve insertion has actually led to an increase in the number of referrals for surgical PVR. The placement of a sur gical valve gives the interventional cardiologist a future landing site for their transcatheter valve. This changes the treatment para digm from valve deterioration, leading not to another operation but to a transcatheter intervention. My first question then is this: Has the introduction of the percutaneous pulmonary valve changed your management paradigm for these patients?

Dr Chen. Thank you very much for the comments and the question.

Regarding whether the criteria for pulmonary valve reinterven tion differ with the advent of transcatheter valves, I do not believe there is a difference. The same indications for valve reintervention, namely symptomatic PR or an RVEDVI of greater than $150 \mathrm{ml} / \mathrm{m}^{2}$, apply for surgical PVR, as well as transcatheter valve replacement.

I would have to say that the criteria have definitely changed over the duration of our study period toward earlier reintervention and in patients with even mild RV dilation. However, these guidelines again hold for both surgical and transcatheter valve replacement at our institution.

Dr Backer. My second question is directly tied to the title of your article, which was somewhat provocative. If younger age is a predictor of SVD, are you now delaying some pulmonary valve operations despite, for example, an RVEDV of $160 \mathrm{~mL} / \mathrm{m}^{2}$ ? For a patient like that who is, for example, 14 or 15 years old, would you now wait until they are older to place the valve? In other words, is this finding in your article a statistical anomaly, or is it truly something that is going to have a clinical effect?

Dr Chen. I believe our findings could potentially have some significant clinical effect in the future. However, despite the find ings, currently, we would not necessarily endorse delaying surgi cal intervention. At our institution, practices have not changed despite our study results. Again, as you stated, the primary goal is preservation of RV function. If the debate is between whether you want to deal with earlier valve deterioration and an extra op eration versus the complications that come with chronic pulmo nary insufficiency and RV dilatation, specifically arrhythmias and sudden death, I think the majority would not delay surgical in tervention. Therefore because of the potential complications asso ciated with delaying reintervention, our practices have not changed.

On the basis of our results, we do believe that attention should be placed on developing a systematic approach to defining the op timal timing of reintervention and weighing the advantages and disadvantages of delaying surgical intervention. In addition, we believe greater attention should be paid to avoiding oversizing, which was a newer finding in our study. In particular, we will plan to look more closely at the possibility that valve oversizing in relation to body surface area might be contributing to the earlier valve failure seen in our reintervention group.

Dr Backer. My final question relates to the technical details of this operation. Some surgeons routinely do this with aortic cross clamping, and some do this with a beating heart. For many years, our standard approach has been to use a crossclamp for these pa tients. We only use a beating heart strategy in a very complicated reoperation with difficult dissection after a careful bubble study with Valsalva at the beginning of the case with transesophageal echocardiographic analysis showing no evidence of any intracar diac shunts. Reading your article, you had no neurologic compli cations in this series. Whatever your surgical strategy was, it was quite a good one, and perhaps you would like to share with 
us your guideline regarding the indications for crossclamp versus beating heart surgery for pulmonary valve insertion.

Again, I congratulate you on your outstanding results and excel lent presentation.

Dr Chen. The practices differ between the surgeons; however, typically, if there is any residual shunt, these are captured on a preoperative catheterization in which the cardiologist specifi cally probes for a patent foramen ovale or during an intraoperative transesophageal echocardiogram with a bubble study, as you men tioned. In these cases in which a residual shunt is identified, cross clamping would be used.

In addition, crossclamping can be used for better exposure. Oth erwise, we do not necessarily use crossclamping in all patients un dergoing a PVR.

Dr J. William Gaynor (Philadelphia, $P a$ ). I would like to ask one question about the mechanisms of the valve failure. The youn ger age would suggest that perhaps this is an accelerated calcifica tion of the leaflets with degeneration. The oversizing would suggest that perhaps there is distortion of the struts. Do you have any data on the mechanisms of a failure when they differ for those that fail in the younger patients versus those with the oversized valves?

Dr Chen. Aside from whether the primary mode of valve fail ure was PR or PS, we do not have any additional data. As I men tioned, the majority of the patients had echocardiographic or MRI evidence of PR before reintervention. Some patient had a combina tion of both regurgitation and stenosis.

Dr Gaynor. Was there leaflet deterioration or distortion of the struts in any of the valves before explantation?

Dr Chen. Unfortunately, we do not have that information today; however, looking more specifically at individual operative notes would be very useful in determining this.

Dr Richard A. Jonas (Washington, DC). I rise to reinforce the point that Carl Backer was just making about the risks of neuro logic injury. I am sure some of the people in this room have been asked to review cases of severe brain injury or death that have occurred in the not too distant past as we do more and more of these PVRs. It is for sure an important risk if the operation is done with a beating heart.

The problem is often entrainment of air. For example, if you cut into the original outflow patch as you are reopening the sternum and you get frothing in the right heart from the heart action, then that froth can be drawn through the foramen ovale with the heart continuing to beat. Or if you are using a single venous cannula or 2 stage cannula and you are entraining air through the tricuspid valve and the heart is continuing to beat, you can definitely get enough air into the left side to cause severe brain injury.

Therefore another option, if you are not confident, as I am not, that a transesophageal echocardiogram is always going to show you a right to left shunt at the atrial level through a foramen ovale, is to use electrical fibrillation. We find that that this is the best way to do this operation. You do not have to dissect out the aorta. In fact, I am using more and more electrical fibrillation. You can do it at relatively mild hypothermia. Therefore this is my question for you: Are you using ventricular fibrillation?

Dr Chen. Unfortunately, I might have to defer this question to Dr Pigula, who is here representing the group. I cannot comment on that.
Dr Frank Pigula (Boston, Mass). I agree completely with ev erything you said, and we do use electrical fibrillation. We have a very low threshold for either crossclamping or using electrical fi brillation if there is any question regarding the status of the atrial septum. Because the transesophageal echocardiogram is not $100 \%$ sensitive, I am not willing to bet somebody's life on it.

I just want to take this moment to make a couple of other com ments regarding the mode of failure of these valves. I think it is im portant because of the introduction of the percutaneous valve There might be implications for how the current generation of sur gically implanted valve fails and how suitable it will be for a trans catheter valve in the future. In other words, if it were a stenotic failure or a collapse of the struts, that might have a different impli cation on a transcatheter valve than a valve failing because of re gurgitation. Also, we have not really seen valves that have failed from strut collapse or stenosis in these patients.

Over time, our indications have changed. The cardiologists and we do use the same indications for valve placement, and that is usually at an end diastolic volume of about $150 \mathrm{~mL} / \mathrm{m}^{2}$.

However, I do think that our criteria for PVR has changed, and the availability of a percutaneous valve might have influenced that.

Dr Ali Mumtaz (Norfolk, Va). My question is very brief regard ing the Mitroflow valve. I noticed you have a very large experience with that. There was one slide that showed that something was sta tistically significant in this group of patients. Just out of curiosity, of the 58 valves you used, how many of them failed in that 1 year follow up?

Dr Chen. There were a total of 4 patients within the Sorin Mi troflow group who fit our criteria for SVD. There were no reinter ventions in this group.

Dr Mumtaz. That is a significant failure for just 1 year. I have found the same thing in the CE bovine pericardial valve; there is an incidence of early failure in the pulmonary position. That is why I was curious to ask if that is any different.

Dr Chen. There were 4 patients of our 58 in the Sorin Mitroflow group who had the criteria of valve deterioration, none of whom required reintervention. However, it would be very interesting to look at each patient and identify a specific mode of early valve failure.

Dr Jonathan Chen (New York, NY). This might be a question for Frank, too, given that the primary mode of failure was regurgitation, and given that we are assuming that this valve inside of a valve percutaneous strategy will work in the future. I used to always try to oversize these pulmonary prostheses as big as we could, thinking that the mode of failure was going to be a combination of stenosis and regurgitation and that the actual in ternal orifice was going to get smaller and smaller, and therefore they ultimately were going to be able to put a Melody valve inside. For example, if you put a $29 \mathrm{~mm}$ valve in the orthotopic position, then perhaps it could one day provide the support structure for a $25 \mathrm{~mm}$ Melody valve.

But now I am told by our interventionalists that the SAPIEN valve is the only one that is as big as $27 \mathrm{~mm}$. Therefore the question is this: If it is mostly regurgitation and not stenosis, should we be putting in any valves that are over size $27 \mathrm{~mm}$ ?

Dr Pigula. I will answer that one. I think that one of the take home messages I have from this is that oversizing the valve is not necessarily an advantage. For most patients, a $25 \mathrm{~mm}$ valve 
is large enough and provides a suitable landing zone for the current generation of percutaneous valves.

The other information, and I think Bill brought it up, is whether it is calcium metabolism that is leading to the valve deterioration in younger patients or whether it is the fact that those valves are oversized for younger and smaller patients. Therefore I have gone to just sizing a $25-\mathrm{mm}$ valve unless there is an obvious reason to use something larger.

Dr Frank L. Hanley (Stanford, Calif). I just had a few more thoughts about the beating heart and the potential for neurologic injury. It is clearly an extremely important point because it can be devastating.

We did a little study many, many years ago in which we did bubble studies on the right side and then obligatorily had to open the heart in a certain percentage of those patients, and we checked specifically for patent foramen ovale. Of all of the patients who had a negative bubble study result, I think we found patent foramen ovale in $25 \%$ or $30 \%$. Therefore it is clearly not a complete safeguard.
However, we routinely do all of these cases on a warm beating heart. What we do is the bubble study; we do a left-sided and right-sided bubble study. Even then, if the results of both of those are negative, we will proceed with a warm beating-heart procedure. However, I specifically look the anesthesia fellow in the eye-and I guess you have to have the luxury of having at least 2 anesthesia people-but I look the anesthesia fellow in the eye and say, "As long as this right ventricle is open, don't take your eyes off that echo machine." At even the first bubble that goes across, we will then abort and do something else. Most of the time, you are fine; occasionally, you will see 1 or 2 bubbles come across, and then you can make a change. But if you do that, you have a very, very complete safeguard, and you can do most of these on a warm beating heart, I think.

Dr Pigula. The only thing I wanted to add to Dr Hanley's comments is that the other thing I will ask the anesthesiologist to do is make sure the perfusion pressure stays up to keep the aortic valve closed during the case. Therefore I will always ask them to leave it at maybe an extra $10 \mathrm{~mm} \mathrm{Hg}$ higher to give me a little extra margin of safety and to prevent the ventricle for injecting. 